\title{
Human Capital as Source of Innovativeness in Subsistence Small Businesses
}

\author{
Carlos Maria Jardon*
}

\begin{abstract}
Subsistence small businesses (SSB) are very important in developing countries for reducing poverty. Companies in developing countries need innovation in order to compete, and innovation is particularly significant for SSBs, as they are usually less well-prepared for competition. Human capital is the key to improving the situation of poor countries as such human capital improves innovativeness in companies. Nevertheless, human capital is scarce in SSBs and these businesses possibly need the alignment of human capital with strategy to improve their performances. This alignment is achieved by exploiting the dynamic capabilities of human capital management. The aim of this paper is to analyse human capital management and innovativeness in SSBs in the timber industry in a region of Latin America using PLS techniques. The findings suggest that SSBs build human capital management and innovativeness as dynamic capabilities and use human capital management to improve innovativeness.
\end{abstract}

Keywords: Innovativeness; human capital management; Subsistence small business; Latin-America; timber industry; dynamic capabilities

Submitted: May 12th 2016 / Approved: September 11th 2016

\section{Introduction}

Reducing poverty is one of the Millennium Development Goals (UNO, 2000). The existence of areas of extreme poverty is usual in developing countries, (Christensen, Parsons, \& Fairbourne, 2010). One of the tools used by people in these areas to alleviate this situation and to create a means of subsistence for the entrepreneur and his family (Schoar, 2010) is the creation of small businesses (Toledo, Hernández, \& Griffin, 2010). Such subsistence small businesses (SSB) are significant and normal in developing countries; because people in such countries are forced into self-employment or start-up businesses, as there are no other alternatives available.

Companies in developing countries need innovation to compete, being particularly important for SSBs, as they usually are less wellprepared for competition (Wu, Lin, \& Hsu, 2007). As noted by Gopalakrishnan \& Damanpour (1997, p. 22) the "ability of the firm to innovate" is called innovativeness, which is an important dynamic capability, obtained by building, integrating, and reconfiguring resource packages (Teece, Pisano, \& Shuen, 1997). The deployment of organizational capabilities and the harnessing the environment supplement the process to obtain dynamic capabilities, which generate value for the customer..

Innovation may serve as the basis for competitive advantage. In this case there are a link between knowledge and innovation (SantosRodrigues, Figueroa Dorrego, \& Fernandez-Jardon, 2008), which is a consequence of the essence of innovation, characterized as the pursuit of new knowledge for discovery.

Human capital (HC) is the key to improving the situation of less developed countries as it enhances the performance of companies. Bruhn, Karlan \& Schoar (2010) propose that managerial capital is the missing ingredient in developing countries. This capital is part of the HC of managers. The intellectual capital based-view suggests that $\mathrm{HC}$ is a source of competitive advantage (Jin, Hopkins, \& Wittmer, 2010), and in particular, a source of innovativeness (Leitner, 2011).

The SSBs have few tangible resources; therefore, the creativity of people in generating competitive advantages is of pivotal importance. The alignment of human capital with an innovation strategy improves innovativeness, which may enhance performance and culminate in competitive advantage (Yen, 2014). This process needs human capital management (HCM). Previous literature proposes different HCM issues as a source of innovativeness (Leitner, 2011); however, the limited resources afforded by the environmental conditions in which SSBs operate potentially limit the development of HCM and innovativeness. In consequence, to improve the growth of SSBs and the economic development of the poorest areas in developing countries, this paper aims not only to analyze HCM and innovativeness in SSBs as dynamic capabilities but also to explore the possible relationships between these capabilities.

Most studies on entrepreneurship have focused on Western Europe or the United States. In Latin American countries, there is a mixture of Western immigration and indigenous cultures that influence business characteristics. This study analyses the subsistence entrepreneur (Toledo et al., 2010), as the characteristics of such entrepreneur, are seen most clearly in SSBs, as their managers and employees often have little training.

In Part 1, the paper expounds the theoretical structure of the study, introducing the working hypotheses. In Part 2, the methodology is presented, followed, in Part three by a case study that analyses the questions addressed. Finally, in Part 4, the conclusions and considerations for the management are discussed.

*Department of Applied economics ECOBAS, University of Vigo, Spain IDLab, National Research University Higher School of Economics, Russia E-mail: cjardon@uvigo.es 


\section{Theoretical structure}

SSBs are businesses created to "merely provide an alternative employment opportunity to the entrepreneur and potentially their family members"(Schoar, 2010; p. 59). Such businesses involve family businesses or single-family member entities. They tend to move on the border of the formal and informal sectors, and may become sucked into the underground economy (Schoar, 2010); this makes it both more difficult for them to obtain public support and also exposes their rivals to unfair competition.

The concept of HC has its origins in the economic literature, defined by Becker (1964) as '... the knowledge, information, ideas, skills, and health of individuals' (Becker, 1964: 1). The skills can be different for managers and workers. Managerial skills comprise technical, human, and conceptual abilities. Technical abilities are described as a manager's specialised and analytical abilities within his or her speciality. These abilities are unusual in SSBs. Human abilities are a manager's ability to work effectively with people. Managers of SSBs probably have these abilities. Conceptual skills are a manager's ability to view an organization from a broad system perspective. Conceptual abilities are unusual in managers of SSBs. These skills belong to managerial capital, which capital is needed in developing countries to not only identify customer needs, but also to help better predict financial needs, and to further facilitate the hiring of top employees (Bruhn et al., 2010).

Workers' skills include technological and relational skills technological abilities comprise problem-solving skills, operations knowledge, and creativity (Jin et al., 2010). Such skills are not usual in SSBs. Workers' relational skills include the ability to relate to others; they are of extraordinary significance in a teamwork environment. Such skills can exist in SSBs.

Individual abilities are often linked to local knowledge, showing expertise in traditional production techniques and knowledge of the specific products and systems of the territory.

SSB entrepreneurs have a strong motivation to support families (Schoar, 2010), and use intuition, personal experience and business sentiment to take decisions (C.M. Jardon \& Martos, 2012). However, they tend to be individualistic, preventing cooperation between competitors. Owner-managers often have a little formal education (London, Anupindi, \& Sheth, 2010), and a poor strategic vision, limited technical and management skills, and little or no strategic planning. They are often bereft of professional expertise, without a market orientation (Jardon, Gutawski, Martos, Aguilar, \& Barajas, 2007) and deficient in experience in costing products (London et al., 2010). SSBs have unskilled workers, as they have greater difficulties in finding trained personnel (Carlos Maria Jardon et al., 2007).

While HC checks the characteristics which distinguish a source enjoying a competitive advantage, it is unclear whether the resulting impact is direct or it must be combined with other factors to generate better performance. Theorists are usually focused on the need to develop a pool of HC that "has either higher levels of skills (general and/or firm specific), or [can achieve] a better alignment between the skills represented in the firm and those required by its strategic intent" (Wright et al., 2001,704). The ability to calibrate the alignment is limited in SSBs as their strategic management is deficient. The stock of $\mathrm{HC}$ can change over time and, consequently, it must constantly be supervised to match the strategic needs of an organization. Possibly this mechanism is dependent on the organization's dynamic capabilities (Teece et al., 1997).

Organizations require dynamic capabilities to adapt effectively to changing market conditions and to create an appropriate value for each situation. This issue is valid for SSBs as they need to innovate using their resources and capabilities. In light of their limited technological and financial resources, SSBs must, necessarily, have recourse to human resources to innovate. The core dynamic capability associated with HC is the HCM.

HCM is a strategic approach to people management, focused on the knowledge, skills, abilities and capacities possessed by individuals in an organization to innovate and to compete. It involves the development of all labor-related issues influencing an organization's strategic and operational objectives. It includes not only the utilization of people but also the development, use, and maintenance of resources, as well as the provision of compensation for services rendered according to the requirements of the job and organization. In consequence, the management system is essential to HCM (Marrewijk \& Timmers, 2003) mostly on SSBs. The relationships between workers are usually informal in SSBs; therefore, instruments, such as teamwork or internal communication - that facilitate relationships-are necessary. The corporate culture depends on a particular territory and the specific characteristics of the owner. This culture conditions the attitudes of workers (Ritchie \& Brindley, 2005); therefore, in SSBs, a way of management integrated with local culture is essential to HCM. Similarly, the ability to transmit experiences facilitates the management of $\mathrm{HC}$, because the learning in SSBs is basically acquired through experience (Hatch \& Dyer, 2004).

Innovativeness is the capacity and commitment of a firm to innovate by reflecting its activities regarding its technological and behavioral aspects (Santos-Rodrigues et al., 2008). We consider innovativeness to be a dynamic capability. Dynamic capabilities are a combination of resources and competencies oriented to performance by the firm. In consequence, innovativeness is the combination of organizational culture, processes, resources and abilities, oriented to innovation. These resources are scarce in SSBs and the central one is usually the creativity of workers. Innovativeness in SSBs is not formalized, being based rather on the necessity to generate elemental innovations to compete. In fact, the processes in SSBs are incipient. SSBs have not design and research and development (R\&D) departments. In consequence, design and R\&D processes are informal, oriented to improving particular issues relating to the organization itself or to enhancing products. Logistics processes and marketing are poorly developed and based on the intuition of the manager. The most formalized activity is the production process, but it is frequently very basic and not oriented 
to innovation. Organizational capabilities are thus in their developmental phase, because technological resources and intellectual capital are very limited, there is little routinization. The innovation culture depends on the entrepreneurial ethos and commonly, on entrepreneurial creativity. Technology is scarce and associated with tangible resources as the source of innovation. Mendoza-Ramírez \& ToledoLópez, (2014) suggest, however, that entrepreneurs are introducing innovative and proactive practices to SSBs.

Previous literature, citing various reasons, suggests that HC increases innovativeness (Yen, 2014). For example, firms with highly skilled and knowledgeable employees have higher levels of $\mathrm{HC}$ and are more likely to create knowledge and make decisions, resulting in better organizational innovativeness (Saá-Pérez, Díaz-Díaz, \& BallesterosRodríguez, 2012). Firm-specific training is necessary because it improves technical abilities to solve problems. The firm must reorganize training activities in ways that generate new understandings and new ideas. Thus, training in core skills is useful for product innovation, although such training in SSBs rarely occurs. On the other hand, Latin American SSBs, in particular, have little concern for the customer, but often have great concern for product quality (Jardon et al., 2007). This interest facilitates product innovation.

Nevertheless, it is hard to know how to encourage employees to contribute their knowledge for the advantage of the organization. In large and medium companies, "people may be reluctant to share crucial knowledge for fear of losing ownership, a position of privilege or superiority" (Tsan \& Chang, 2005, p. 7), but in SSBs this problem is unusual, as the shared knowledge is not a strategic asset. For the benefits of the organization, managers should thus raise awareness of the importance of innovation and provide incentives for employees to develop innovative mindsets. SSBs do not generally provide financial incentives; therefore, they should motivate using social incentives based on values and attitudes. Managers should emphasize the development of employee capability as well as employee zeal. Therefore, HC should focus both on employee competencies (e.g. skills, know-how, and aptitudes), and on employee commitments (e.g., willingness to devote themselves to, and work for, the company). Previous studies have suggested that organizational innovativeness is closely related to $\mathrm{HC}$ and organizational learning (Santos-Rodrigues et al., 2008). Subramaniam and Youndt (2005) tested the relationship between $\mathrm{HC}$ and innovativeness, concluding that $\mathrm{HC}$ negatively affects the potential for radical innovation, but indirectly influences the capacity for incremental innovation. Possibly, HC needs a mediator to affect innovativeness. Usually SSBs, in adopting an innovation, favor incremental. The mechanisms used to adopt an innovation are generally based on people; however, the people need to know the underlying aim of the chosen strategies. Thus, SSBs should combine $\mathrm{HC}$ with organizational issues, processes and systems to constitute a dynamic capability to improve innovativeness. The literature defines this dynamic capability as HCM.

HCM combines HC and organizational capabilities with strategy for innovating. The culture and training of workers facilitate their ability to innovate on processes and products (McAdam, Reid, \& Shevlin, 2014) the emergence of the knowledge economy may enable leveraging of knowledge to address such innate limitations. The aim of this study is to twofold. First, the study explores how SMEs in peripheral areas, i.e. challenging regions, seek to implement innovation from a path perspective by examining the contributions from antecedent and mediator variables or constructs, including knowledge-based factors identified in the literature, using a cross-sectional survey of SMEs at firm level. Second, to further examine how these path model constructs and relationships contribute in a causal manner to innovation implementation at an activity level of analysis based on knowledge-based view and dynamic capability theory, using a case study analysis. Design/ methodology/approach - A sequential mixed method approach is used. In relation to the first aim a hypothetical path model is tested using structured equation modelling techniques based on a cross-sectional survey of SMEs in peripheral regions ( $n=604$. The existence of internal communication fosters relationships between workers, providing an information system that is usually very informal, but providing flexibility to the company, and facilitating innovation (Jin et al., 2010). The management system enables the organization of the processes and systems associated to innovate; and the professionalization of HR, and the ability to transmit experiences, enhance training and the better use and deployment of limited technology—-thereby also fostering innovation.

Local knowledge in developing countries is different than local knowledge in developed countries. Therefore, taking cognizance of such cultural variations and ensuring that local knowledge is harnessed and put to the service of innovation enhances the competitiveness of enterprises. This local knowledge is part of HC. The process of transforming this local knowledge to innovativeness depends on the ability to manage the HC, that is, the HCM. Consequently, we can thus introduce the following hypothesis:

H1: SSBs need to organize their HC through HC management to improve their innovativeness.

\section{Methodology and information sources}

This study focused on SSBs, and, particularly, the timber SSBs, located in Oberá ('the shining', in Guarani) Department. This area is in the northeast of Argentina. A large proportion of immigrants has brought singular cultural characteristics to this area. It is a landscape studded not only with agricultural and forest crops-yerba mate, tea, and snuff-but also large wood plantations occupying more than $75 \%$ of the territory (INDEC, 2002). The population includes 162 timber companies (MERNRyT, 2003)—mainly sawmills and carpentry. The wood industry is under development, albeit, with little evidence of professionalism. Of the few companies that have imported hardware from abroad, the machinery is mostly outdated. Support services and complementary activities are scarce (Carlos Maria Jardon et al., 2007). Usually, the companies in existence are small or micro enterprises which-due to the low survival rate-have traded for only a few years (see Table 1). All these features suggest that these companies are SSBs.

Data were collected from a survey of owners and managers of timber SSBs in Oberá in late 2005 and early 2006, resulting in 113 responses, with a sampling error of $5.09 \%$. The study realizes a test of homogeneity to ensure that the conformation of sample and population. 
Table 1: Characteristics of the sample (number of firms)

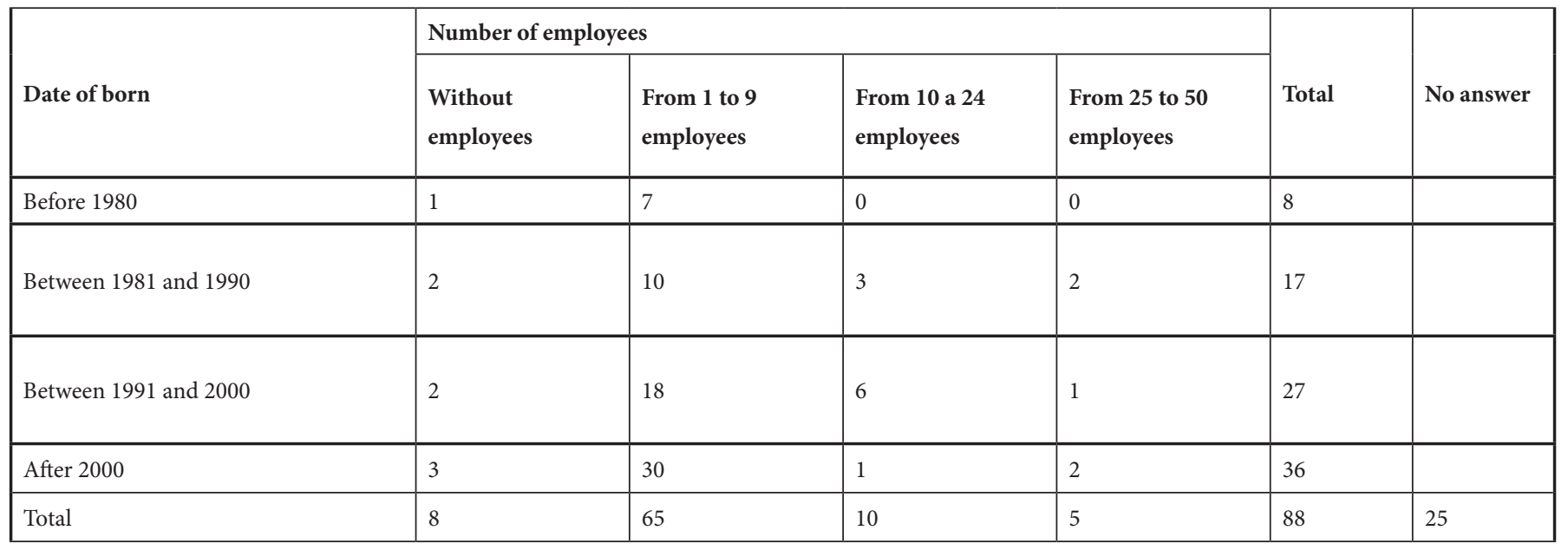

To measure the constructs related to the process of generating dynamic capabilities oriented to innovation, the study used a questionnaire with a Likert scale according to Jardon and Martos (2012) and based on scales referred to in the literature (Tsan \& Chang, 2005).
It questioned owner-managers on the importance of each item (see Table 2) as a source of competitive advantage for their companies, ranging from 1 (not important as a source of competitive advantage) to 5 (very important as a source of competitive advantage).

Table 2: Competitive advantages items

\begin{tabular}{|l|l|l|}
\hline \multicolumn{1}{|c|}{ Competency } & \multicolumn{1}{|c|}{ Source } & \multicolumn{1}{c|}{ Reference } \\
\hline \multirow{5}{*}{ Innovativeness } & The capacity for innovation in processes, products or markets & (Verhees, Meulenberg, \& Pennings, 2010) \\
\cline { 2 - 3 } & Process and product technologies & (Camisón-Zornoza, 2004) \\
\cline { 2 - 3 } & Technological resources of facilities and equipment & (Verhees, Meulenberg, \& Pennings, 2010) \\
\cline { 2 - 3 } & The Design process & (Hausman, 2005) \\
\cline { 2 - 3 } & The Research, development and innovation process & (Hausman, 2005) \\
\cline { 2 - 3 } & Information system & (Khasawneh, 2008) \\
\hline \multirow{5}{*}{$\begin{array}{l}\text { HC } \\
\text { Management }\end{array}$} & The training of managers and workers & (Camisón-Zornoza, 2004) \\
\cline { 2 - 3 } & Internal communication & (Camisón-Zornoza, 2004) \\
\cline { 2 - 3 } & The Corporate Culture & (Jardon \& Martos, 2012) \\
\cline { 2 - 3 } & Team working & (Camisón-Zornoza, 2004) \\
\cline { 2 - 3 } & The professionalism and attitude of managers and workers & (Hatch \& Dyer, 2004) \\
\cline { 2 - 3 } & Human resources & (Jardon \& Martos, 2012) \\
\cline { 2 - 3 } & The Ability to transmit experiences & (Marrewijk \& Timmers, 2003) \\
\cline { 2 - 3 } & Management system & (Jardon \& Martos, 2012) \\
\cline { 2 - 3 } & The ability to evaluate investment risks & (Jartos, 2012) \\
\cline { 2 - 3 } & The attitude of cooperation and partnerships by the company & \\
\hline
\end{tabular}

The research used the partial least squares technique (PLS) (Vinzi, Wynne, Chin, \& Henseler, 2010) to test the relationships between HCM and innovativeness. The aim of PLS-based solutions is to minimize the variance of all dependent variables regarding causal variables. This technique does not require an assumption of the normality of variables-which was problematic to verify in this case, as the study measures the items on a Likert scale. Also, this approach avoids problems such as identification parameters, a common problem in covariance models (Vinzi et al., 2010). PLS uses the average variance extracted (AVE) and Cronbach's alpha (CA), as criteria to validate the model. AVE assesses the variance caught by a latent construct. CA determines the internal consistency to establish the reliability of the measuring instrument and data collection (Nunnally \& Bernstein, 1994). The limits used were 0.5 for AVE (Vinzi et al., 2010) and 0.6 for CA (Nunnally \& Bernstein, 1994). The law of distribution of the estimators was unknown. In consequence, the study used bootstrapping to evaluate the t-statistics and calculate p-values (Vinzi et al., 2010). The software used for data analysis was Smart-PLS (Ringle, Wende \& Will, 2005). 


\section{Empirical analysis}

The constructs of HCM and innovativeness were used to test the model. First, the study verified the components of each construct. Table 3 shows the final estimate of the factor loadings, CA and AVE, for each construct. The items that comprise the constructs are weighty, confirming the previous analysis. The relationships between latent and manifest variables are all significant.

HCM is fundamentally constituted by three influences: the $\mathrm{HC}$ of the company (Jin, Hopkins \& Wittmer, 2010); the culture and the internal communication that facilitate HR management; and, the organizational capabilities related to management (Marrewijk \& Timmers, 2003). SSBs present issues similar to those of large enterprises, but the contents of these issues are different. HC includes the training and professionalization of human resources, but, in SSBs, training is scant, informal, and is consequence of the accumulation of knowledge or skill that results from direct participation in events or activities, therefore, the ability to transmit experiences is essential to HCM (Jardon \& Martos, 2012). Professionalization of HR is limited and oriented to local know-how (Jardon et al., 2007). Managerial capital in SSBs shows an authoritarian leadership (Gibbons \& Connor, 2005). Companies need management systems to orient HR to strategy. SSBs have a management systems based on intuition, personal experience and business sentiment (C.M. Jardon \& Martos, 2012); these characteristics necessarily shape the organization of
HR. These companies often adopt a conservative strategic posture; therefore, they often have to undergo incremental strategy formation processes (Gibbons \& Connor, 2005). The lack of organizational systems in SSBs highlights the need for a cohesive corporate culture incorporating the different components of HCM. In consequence, the manifestation of local norms in the company culture is essential to HR management (Ritchie \& Brindley, 2005).

Innovativeness includes elements that directly facilitate innovation, such as technologies (Camisón-Zornoza, 2004), the innovation capacity of HR (Verhees, Meulenberg, \& Pennings, 2010) and the organizational capabilities directly related to innovation such as the information system (Khasawneh, 2008) or R \& D and design processes (Hausman, 2005). Again, although the aspects that make up innovativeness are similar to those of other companies, SSBs, in particular, understand these components. The technology of SSBs is very rudimentary and it utilizes fundamentally the tangible resources. The intuitive management system leads companies to use their tangible resources for innovativeness. This result may be a consequence of the fact that technologies are scarce in SSBs and, so, the companies use their technological resources as a source of innovation (Verhees, Meulenberg, \& Pennings, 2010). The innovativeness employs principally the creativity and, as with the process of design and R \& D, is oriented towards the improvement of a particular process or product. The information system is informal and closely associated with the internal communication of HR.

Table 3: Measures of sources of competitive advantages

\begin{tabular}{|c|c|c|c|c|}
\hline Construct & item & weigth & T-Stat & $P$ value \\
\hline \multirow{6}{*}{$\begin{array}{l}\text { INNOvativeness } \\
\mathrm{CA}=0.895 \\
\mathrm{AVE}=0.588\end{array}$} & The design process & 0.18 & 8.05 & 0.000 \\
\hline & Information system & 0.188 & 10.26 & 0.000 \\
\hline & The Research, development and innovation process & 0.155 & 6.57 & 0.000 \\
\hline & The capacity for innovation in processes, products or markets & 0.267 & 10.22 & 0.000 \\
\hline & Process and product technologies & 0.242 & 10.24 & 0.000 \\
\hline & Technological resources of facilities and equipment & 0.262 & 11.11 & 0.000 \\
\hline \multirow{10}{*}{$\begin{array}{l}\mathrm{HC} \text { management } \\
\mathrm{CA}=0.919 \\
\mathrm{AVE}=0.534\end{array}$} & The management system & 0.103 & 5.96 & 0.000 \\
\hline & The attitude of cooperation and partnerships by the company & 0.12 & 8.02 & 0.000 \\
\hline & The ability to transmit experiences & 0.141 & 7.34 & 0.000 \\
\hline & Internal communication & 0.129 & 9.93 & 0.000 \\
\hline & The training of managers and workers & 0.155 & 11.68 & 0.000 \\
\hline & The professionalism and attitude of managers and workers & 0.129 & 10.16 & 0.000 \\
\hline & The ability to evaluate investment risks & 0.139 & 11.81 & 0.000 \\
\hline & The corporate culture & 0.16 & 9.54 & 0.000 \\
\hline & Human resources & 0.15 & 10.26 & 0.000 \\
\hline & Team working & 0.137 & 6.651 & 0.000 \\
\hline
\end{tabular}

Table 4 shows the results of the model estimation by PLS. We accept H1. In this sense, SSBs exhibit a behavior similar to other companies regarding innovativeness (McAdam et al., 2014)the emergence of the knowledge economy may enable leveraging of knowledge to address such innate limitations. The aim of this study is to twofold. First, the study explores how SMEs in peripheral areas, i.e. challenging regions, seek to implement innovation from a path perspective by examining the contributions from antecedent and mediator variables or constructs, including knowledge-based factors identified in the literature, using a cross-sectional survey of SMEs at firm level. Second, to 
further examine how these path model constructs and relationships contribute in a causal manner to innovation implementation at an activity level of analysis based on knowledge-based view and dynamic capability theory, using a case study analysis. Design/methodology/ approach - A sequential mixed method approach is used. In relation to the first aim a hypothetical path model is tested using structured equation modelling techniques based on a cross-sectional survey of
SMEs in peripheral regions ( $\mathrm{n}=604$. Hayton (2003) shows the importance of HCM in improving innovativeness in SMEs in developed countries. SSBs use an intuitive management system (Gibbons \& Connor, 2005); therefore they use generic elements of HC-such as the training and attitude of HR - as the basis of HCM. The management system associated with the characteristics of the owner-manager is crucial in allowing these companies to innovate.

Table 4: effects and t-statistics

\begin{tabular}{|l|l|l|l|}
\hline & \multicolumn{1}{|c|}{ Effect } & \multicolumn{1}{|c|}{ T Statistics } & \multicolumn{1}{c|}{ P-value } \\
\hline HC management $>$ Innovativeness & 0.779 & 23.62 & 0.000 \\
\hline
\end{tabular}

\section{Conclusions}

The wealth of the poorest areas of developing countries depends on the growth of SSBs (Toledo, Hernández, \& Griffin, 2010). Innovativeness is very necessary to grow SSBs (Mahemba \& Bruijn, 2003); therefore, it is desirable to detect the factors that encourage innovativeness. The research shows that HCM improves innovativeness in SSBs. HC is a source of innovation (Leitner, 2011); however; the mediators of this effect are not well established. Some authors suggest that this impact occurs through dynamic capabilities (Santos-Rodrigues et al., 2008); however, this process can be different in SSBs. This paper has provided further research by introducing mechanisms of dynamic capabilities as mediators between HC and innovativeness in SSBs.

The findings suggest that the training and attitude of HR (Jin et al., 2010; Saá-Pérez et al., 2012), corporate culture (Ritchie \& Brindley, 2005), the ability to transmit experiences, internal communication (Jardon \& Martos, 2012) and the management system (Marrewijk \& Timmers, 2003) constitute HCM in SSBs. Innovativeness includes elements that directly facilitate innovation, such as technological resources (Verhees et al., 2010), the innovation capacity of HR (Verhees et al., 2010) and organizational capabilities directly related to innovation such as the information system (Khasawneh, 2008) or R \& D and design processes (Hausman, 2005).

In consequence, this paper provides ideas for improving the strategic management of SSBs. First, the basis of innovativeness is HC, (Leitner, 2011; Wu et al., 2007; Yen, 2014). Managerial capital is needed in developing countries to improve innovativeness (Bruhn et al., 2010). The training of human resources improves innovativeness (Saá-Pérez et al., 2012). Actions to foster HC are, thus, needed; therefore, training policies should be pursued, especially in organizational and strategic management and technology (Anand et al, 2006). In SSBs, this learning is especially needed in the case of the owner-manager, to determine the organizational structure and the cultural foundations of the company (Jardon et al., 2007). The training of managers and workers requires the joint action of social agents.

Second, innovativeness requests technology and technological resources (Correia da Silva Andrade, Will, Breda Mascarenhas, Campos da Silva, \& de Oliveira Gomes, 2015); therefore, it is necessary to promote modernization of technological structures and training. To foster the use of technology, educational systems must look towards professionalizing their students to meet business needs, as these are increasing in proportion to the technological advancement of society. SSBs need the support of regional governments (McAdam et al., 2014)the emergence of the knowledge economy may enable leveraging of knowledge to address such innate limitations. The aim of this study is to twofold. First, the study explores how SMEs in peripheral areas, i.e. challenging regions, seek to implement innovation from a path perspective by examining the contributions from antecedent and mediator variables or constructs, including knowledge-based factors identified in the literature, using a cross-sectional survey of SMEs at firm level. Second, to further examine how these path model constructs and relationships contribute in a causal manner to innovation implementation at an activity level of analysis based on knowledge-based view and dynamic capability theory, using a case study analysis. Design/methodology/approach - A sequential mixed method approach is used. In relation to the first aim a hypothetical path model is tested using structured equation modelling techniques based on a cross-sectional survey of SMEs in peripheral regions ( $\mathrm{n}=604$, possibly by programs based on mentoring and 'learning by doing' (Ambrosini, Bowman, \& Collier, 2009). Also, a lack of experience in costing products can also increase the capacity to benefit from formal institutions that disseminate business or technological information (London et al., 2010).

Third, companies need to adopt HCM to achieve dynamic capability, combining different elements of HC with organizational capabilities to improve their innovativeness; HCM is the mechanism that connects $\mathrm{HC}$ and the innovativeness of SSBs. This combination needs the strategic orientation of owner-managers. In consequence, training institutions should promote entrepreneurial competencies, possibly by professionalizing the managers of SSBs by integrating dynamic capabilities with short-term economic performance, thereby enhancing their strategic vision.

Fourth, the impact of HCM on innovativeness suggests that the effectiveness of $\mathrm{HC}$ is a consequence of social context. The introduction of SSBs in a social context facilitates the management of $\mathrm{HC}$ and therefore improves the innovativeness of such entities (Wright et al., 2001).

This research studied SSBs in the timber industries in a particular region of Argentina, qualifying its applicability to other industries or areas. 
Nevertheless, the economic organization of these SSBs is very similar to other types of activities, especially those based on natural resources. To support the findings is convenient to extend studies to other activities in developing countries.

The study employed cross-sectional data, which does not allow support temporal causality. Also, the conjuncture of causes may imply relations of an accidental type, as the data solely related to a given period. A possible alternative in the context of a future study to improve the research would be to use panel data.

Biographical notes: Carlos M. Jardon is Professor of Econometrics at the University of Vigo. PhD in Economics and Mathematics from the University of Navarre (Spain). He has published many books in Spanish on the quantitative economics applied to the business and Finance, specially related to Galician and Latin-American SMEs in collaboration with other authors.

\section{References}

Ambrosini, V., Bowman, C., \& Collier, N. (2009). Dynamic Capabilities: An Exploration of How Firms Renew their Resource Base. British Journal of Management, 20, S9-S24.

Anand, J., Brenes, E., Karnani, A., \& Rodriquez, A. (2006). Strategic responses to economic liberalization in emerging economies: Lessons from experience. Journal of Business Research, 59(3), 365-371.

Becker, G. (1964). Human Capital. New York: Columbia U. Press.

Bruhn, B. M., Karlan, D., \& Schoar, A. (2010). What Capital is Missing in Developing Countries? American Economic Review: Papers \& Proceedings, 100(May), 629-633.

Camisón-Zornoza, C. (2004). Shared, Competitive and Comparative Advantages: A Competence-Based View of the Competitiveness of Industrial Districts. Environment and Planning, 36(12), 2227-2256.

Christensen, L. J., Parsons, H., \& Fairbourne, J. (2010). Building Entrepreneurship in Subsistence Markets: Microfranchising as an Employment Incubator. Journal of Business Research, 63(6), 595-601.

Correia da Silva Andrade, L. P., Will, M., Breda Mascarenhas, L. A., Campos da Silva, R., \& de Oliveira Gomes, J. (2015). Evaluation of Technological Trends and Demands of the Manufacturing Industry to a Center of R \& D \& I. Journal of Technology Management \& Innovation, 10(3), 104-119.

Gibbons, P. T., \& Connor, T. O. (2005). Influences on Strategic Planning Processes among Irish SMEs. Journal of Small Business Management, 43(2), 170-186.

Gopalakrishnan, S., \& Damanpour, F. (1997). A review of innovation research in economics, sociology and technology management. Omega, 25(1), 15-28.
Hatch, N. W., \& Dyer, J. H. (2004). Human capital and learning as a source of sustainable competitive advantage. Strategic Management Journal, 25(12), 1155-1178.

Hausman, A. (2005). Innovativeness among small businesses: Theory and propositions for future research. Industrial Marketing Management, 34(8), 773-782.

Hayton, J. C. (2003). Strategic human capital management in SMEs: An empirical study of entrepreneurial performance. Human Resource Management, 42(4), 375-391.

INDEC. (2002). Censo Nacional agropecuario. Retrieved November 4, 2005, from http://www.indec.mecon.ar

Jardon, C. M., Gutawski, S., Martos, S., Aguilar, C., \& Barajas, A. (2007). Visión estratégica de la cadena empresarial de la madera de Oberá, Misiones. Posadas: EDUNAM - Editorial Universitaria de la Universidad Nacional de Misiones.

Jardon, C. M., \& Martos, M. S. (2012). Intellectual capital as competitive advantage in emerging clusters in Latin America. Journal of Intellectual Capital, 13(4), 457-484.

Jin, Y., Hopkins, M. M., \& Wittmer, J. L. S. (2010). Linking Human Capital to Competitive Advantages: Flexibility in a Manufacturing Firm's Supply Chain. Human Resource Management, 49(5), 939-963.

Khasawneh, A. M. (2008). Concepts and measurements of innovativeness: the case of information and communication technologies. International Journal of Arab Culture, Management and Sustainable Development, 1(1), 23-33.

Leitner, K.-H. (2011). The effect of intellectual capital on product innovativeness in SMEs. International Journal of Technology Management, 53(1), 1-18.

London, T., Anupindi, R., \& Sheth, S. (2010). Creating mutual value: Lessons learned from ventures serving base of the pyramid producers. Journal of Business Research, 63(6), 582-594.

Mahemba, C. M., \& Bruijn, E. J. De. (2003). Innovation Activities by Small and Medium-sized Manufacturing Enterprises in Tanzania. Creativity and Innovation Management, 12(3), 162-173.

Marrewijk, M. van, \& Timmers, J. (2003). Human Capital Management : New Possibilities in People Management. Journal of Business Ethics, 44(2-3), 171-184.

McAdam, R., Reid, R., \& Shevlin, M. (2014). Determinants for innovation implementation at SME and inter SME levels within peripheral regions. International Journal of Entrepreneurial Behaviour \& Research, 20, 66-90. 
Mendoza-Ramírez, L., \& Toledo-López, A. (2014). Strategic orientation in handicraft subsistence businesses in Oaxaca, Mexico. Journal of Marketing Management, 30(5-6), 476-500. http://doi.org/10.1080 /0267257X.2014.893248

MERNRyT. (2003). Primer compendio cuatrienal estadístico sobre el sector foresto industria de la provincia de Misiones. Posadas: Ministerio de Ecología, R.N.R. y Turismo de Misiones.

Nunnally, J., \& Bernstein, I. (1994). Psychometric Theory (3th ed.). New York: McGraw-Hill Humanities/Social Sciences/Languages.

Ringle, C. M., Wende, S., \& Will, A. (2005). SmartPLS Release: 2.0 (beta). Retrieved from http://www.smartpls.de

Ritchie, B., \& Brindley, C. (2005). Cultural determinants of competitiveness within SMEs. Journal of Small Business and Enterprise Development, 12(1), 104-119.

Saá-Pérez, P. De, Díaz-Díaz, N. L., \& Ballesteros-Rodríguez, J. L. (2012). The role of training to innovate in SMEs. Innovation, 14(2), 218-230.

Santos-Rodrigues, H., Figueroa Dorrego, P., \& Fernandez-Jardon, C. (2008). Knowledge and Innovativeness. The International Journal of Knowledge, Culture \& Change Management, 7(8), 87-92.

Schoar, A. (2010). The Divide between Subsistence and Transformational Entrepreneurship. In J. Lerner \& S. Stern (Eds.), Innovation Policy and the Economy, Volume 10 (Vol. 10, pp. 57-81). Chicago: University of Chicago Press.

Subramaniam, M., \& Youndt, M. A. (2005). The influence of intellectual capital on the types of innovative capabilities. Academy of Management Journal 48(3), 450-463.
Teece, D. J., Pisano, G., \& Shuen, A. (1997). Dynamic Capabilities and Strategic Management. Strategic Management Journal, 18(7), 509-533.

Toledo, A., Hernández, J. D. L. P., \& Griffin, D. (2010). Incentives and the growth of Oaxacan subsistence businesses. Journal of Business Research, 63(6), 630-638.

Tsan, W., \& Chang, C. (2005). Intellectual capital system interaction in Taiwan. Journal of Intellectual Capital, 6(2), 285-298.

UNO. (2000). United Nations Millennium Declaration. Retrieved December 25, 2010, from http://www.un.org/millennium/declaration/ares552e.htm

Verhees, F. J. H. M., Meulenberg, M. T. G., \& Pennings, J. M. E. (2010). Performance expectations of small firms considering radical product innovation Journal of Business Research, 63(7), 772-777.

Vinzi, V. ., Wynne, W., Chin, W., \& Henseler, J. (2010). Handbook of Partial Least Squares: Concepts, Methods and Applications. Berlin: Springer Science \& Business Media.

Wright, P. M., Dunford, B. B., \& Snell, S. A. (2001). Human resources and the resource based view of the firm. Journal of Management, 27(6), 701-721.

Wu, S.-H., Lin, L.-Y., \& Hsu, M.-Y. (2007). Intellectual capital, dynamic capabilities and innovative performance of organisations. International Journal of Technology Management, 39(3/4), 279-296.

Yen, Y.-F. (2013). The impact of bank's human capital on organizational performance: How innovation influences performance. Innovation 15(1), 112.117 